\title{
The Long-Term Care Insurance Market
}

\author{
Denis Kessler \\ Immeuble SCOR, 1, Avenue Général de Gaulle, 92074 Paris La Défense Cedex, France. \\ E-mail: dkessler@scor.com
}

This paper focuses on the existence of an insurance market for long-term care. There are three major risks for insurers that provide long-term care insurance: risk of escalating costs, risk of adverse selection and risk of moral hazard. Despite these risks, the long-term care insurance is a potentially expanding market for insurance companies able to innovate and design products tailored to this very specific demand.

The Geneva Papers (2008) 33, 33-40. doi:10.1057/palgrave.gpp.2510164

Keywords: long-term care insurance; escalating costs; adverse selection; moral hazard: France and the United States; old age

\section{Introduction}

Cicero's Cato Major de Senectute says of being "forgetful and slipshod", that "these are faults that do not attach to old age as such, but to a sluggish, spiritless, and sleepy old age". Our great-grandparents would probably have held a fairly similar opinion. When we consider how topical the issue of long-term care is in contemporary societies, we can measure how far social perceptions of this subject have travelled over the past century. If we listen to Cicero, loss of autonomy is merely the result of indolent behaviour that could not, by definition, be covered by an insurance policy. In actual fact, medicine has taught us that loss of autonomy is only partially due to lifestyle choices, most often made when we are younger, and that genetic determinants as well as the general hiccups of life also have a major role to play. Loss of autonomy is therefore the consequence of random events over which, in the end, we have little control. It can therefore be covered by an insurance policy through traditional market methods. For all that, moral hazard has not disappeared from long-term care, it has simply shifted and remains a key element in the structure and design of products.

\section{Existence of an insurance market for long-term care}

It is a statement of fact that a market exists for the coverage of long-term care. The largest worldwide market is the American market, with over 6 million policyholders and 25 years of experience. The second largest worldwide market, located in Europe, is the French market with around 3 million policyholders, a growth rate of 15 per cent per year and 20 years of experience. Interestingly, these two market leaders are based on two different models of cover for long-term care risks: ${ }^{1}$

\footnotetext{
${ }^{1}$ Cf. Taleyson (2003).
} 
- In the United States, long-term care insurance contracts are generally individual and provide for the reimbursement of care and services costs up to a certain limit, with multiple options. These are products whose philosophy is derived from health insurance products. They are distributed by agents' networks and are tax qualified.

- In France, long-term care insurance contracts can be individual or collective and provide for the payment of a monthly cash benefit, which may be proportionate to the degree of dependency involved and adjusted according to the evolution of this dependency in the latest generation of contracts. These are products whose philosophy is derived from disability annuities products. They are distributed by direct selling networks and are not tax qualified.

In other countries, the private long-term care market remains very narrow, with different trends - rapidly growing in countries such as Spain, Italy and South Korea, but stagnating elsewhere such as in Germany, the United Kingdom and the Nordic countries. This should not be taken as an indication of the difficulty faced by the market in covering this type of risk. In fact, the market has actually been ousted by an aggressive public offer of cover, whose sustainability in the longer term is nonetheless threatened by the inadequate selectivity employed with regard to the facilities put in place, as well as by the wider crisis of the Welfare State. American difficulties can be imputed, at least partially, to the dynamism of the public system of Medicaid. ${ }^{2}$ We should note that in a country like France, where public aid has not been in a position to oust the services proposed by the market, the number of policyholders ( $\sim 3$ million) is significantly higher than the number of people receiving public aid $(\sim 1$ million $)$.

Clearly, the demand for long-term care insurance is also linked to the patrimonial behaviour of the agents involved, particularly with regard to succession. The hazards involved in public aid in the field of long-term care are reminders of this. In a country like France, for as long as such aid has been associated with the local authority's power to reclaim part of the estate of those under long-term care, the latter have been reluctant to use public aid, so as to preserve their ability to leave an inheritance for their nearest and dearest. From this point of view, an insurance structure has the advantage of preserving this ability for people under long-term care.

\section{The nature of loss of autonomy}

Firstly, loss of autonomy should be clearly distinguished from illness, disability and handicap, although these four concepts are not totally independent of each other:

- long-term care denotes an inability to perform some of the most basic everyday activities due to old age (e.g. getting up, dressing, washing, eating, walking and so on) and the need for assistance in order to carry out such activities;

\footnotetext{
${ }^{2}$ Brown et al. (2006) and Brown and Finkelstein (2004).
} 
Table 1 Three ways of measuring loss of autonomy

\begin{tabular}{|c|c|c|}
\hline \multicolumn{2}{|c|}{ Katz scale (used throughout the world) } & \multirow{2}{*}{$\begin{array}{l}\text { The AGGIR scale, the French } \\
\text { national system on which the } \\
\text { personal LTC allowance is based } \\
\text { (used by public authorities and } \\
\text { certain French insurers) }\end{array}$} \\
\hline $\begin{array}{l}\text { Activities of daily life (used by } \\
\text { French insurers) }\end{array}$ & $\begin{array}{l}\text { Activities of daily life (used } \\
\text { by American insurers) }\end{array}$ & \\
\hline Bathing & Bathing & $\begin{array}{l}\text { Bedridden or confined to an } \\
\text { armchair }+ \text { mental faculties } \\
\text { severely impaired }\end{array}$ \\
\hline Dressing & Dressing & $\begin{array}{l}\text { Confined or impaired mental } \\
\text { faculties }\end{array}$ \\
\hline Transferring & Transferring & Help several times a day for ADLs \\
\hline Eating & Toilet use & $\begin{array}{l}\text { Loss of autonomy for more than } \\
\text { one ADL }\end{array}$ \\
\hline - & Eating & $\begin{array}{l}\text { Occasional help for bathing and } \\
\text { home care }\end{array}$ \\
\hline - & Continence & Autonomous \\
\hline $\begin{array}{l}\text { Loss of autonomy }=\text { inability } \\
\text { to carry out } 2 \text { of these } 4 \\
\text { activities without the help } \\
\text { of a third person }\end{array}$ & $\begin{array}{l}\text { Loss of autonomy }=\text { inability } \\
\text { to carry out } 2 \text { of these } 6 \text { activities } \\
\text { without the help of a third } \\
\text { person }\end{array}$ & $\begin{array}{l}\text { Loss of autonomy }=\text { belonging to } \\
\text { one of the first } 4 \text { categories above }\end{array}$ \\
\hline
\end{tabular}

- illness denotes an objective, temporary situation of ill health (such as fever, depression, etc.) and a need for therapeutic care (i.e. medical consultation, medication, surgical intervention, etc.);

- disability denotes a reduced capacity for normal activity following an accident or an illness, and does not necessarily imply the need for assistance;

- handicap denotes a physical or psychological limitation in the accomplishment of normal activity and may be associated with a need for assistance.

Three main analysis grids are used to provide a way of measuring loss of autonomy that aims to be objective. These are summarised in Table 1, which clearly shows their common points.

We can conclude, therefore, that there is an apparent consensus on what is actually included in the long-term care that should be covered by insurers. The material triggers of long-term care are themselves standard: dementia (25-50 per cent of cases), cancer (15-30 per cent of cases), cardiovascular diseases (15-30 per cent of cases), other neuropsychiatric diseases (10-20 per cent of cases), rheumatology (2-10 per cent of cases), accidents (5-10 per cent of cases) and ophthalmic diseases (1-3 per cent of cases).

\section{Nature of long-term care risk for the insurer}

The insurability of a risk depends on the nature of the risk transferred to the cost of the insurer, along with the insurer's ability to correctly price this risk. Materially speaking, long-term care perspectives result from the combination of many random factors: lifespan, lifespan with and without disability, the presence of family support 


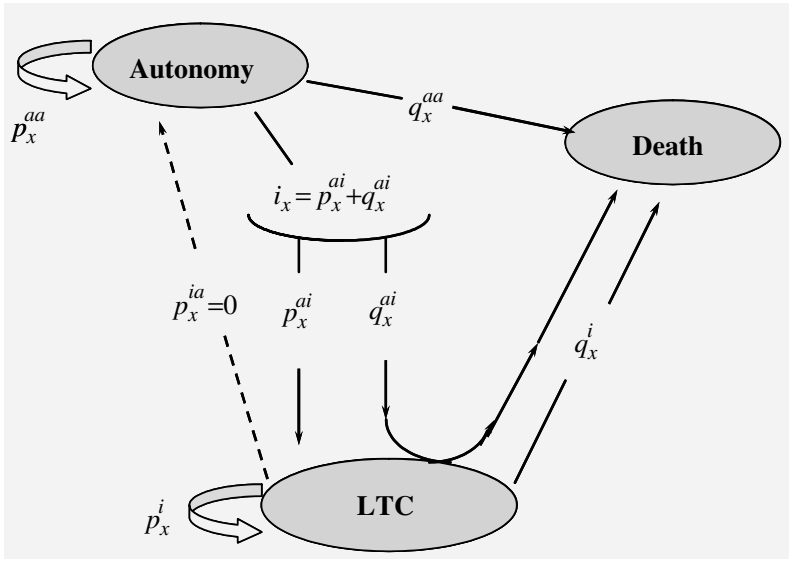

Figure 1. A complex multi-states model.

(spouse survival plays an important role in this respect) and the presence of free public care (cf. Figure 1). ${ }^{3}$ From this point of view, we could sum up long-term care as carrying three major risks for the insurer.

The first risk for the insurer involves the risk of escalating costs. According to some experts, an extension of lifespan goes hand in hand with an extension of the amount of life spent with a disability, that is, in a situation of total or partial loss of autonomy. Long-term care is an emerging risk whose total cost will increase more rapidly than national wealth. This naturally raises the problem of pricing insofar as the underlying trend is still not properly understood, policyholders themselves being inclined to underestimate the impact involved. The risk, therefore, is that supply and demand curves for long-term care products only meet at a point where the services on offer are very restricted or even inexistent. Work based on a comparison of several French statistical sources by the INED and INSERM research institutes nonetheless shows that this fear has not been realised, and that we are not actually experiencing a pandemic of disability, particularly severe disability. In actual fact, over the past 20-25 years we see that life expectancy without loss of autonomy has continued to rise. However, this is more distinct for life expectancy without severe loss of autonomy than for life expectancy without loss of ongoing functional autonomy, more distinct for men than for women and more distinct for the less elderly than for the very elderly. ${ }^{4}$ The same behaviours are observed at the international level: there are as many countries where the number of old disabled people grows more quickly (cf. Belgium, Japan, Sweden) than countries where it grows less quickly (cf. Italy, France, U.S.A.). ${ }^{5}$ Studies into the links between lifestyle and loss of autonomy could also eventually

${ }^{3}$ Cf. Lakdawalla and Philipson (2002).

${ }^{4}$ Cf. Cambois et al. (2006).

${ }^{5}$ Cf. Lafortune and Balestat (2007) and Jacobzone (2000). 
significantly alter the trends observed in the past, once these studies enable the development of efficient prevention techniques.

The second risk for the insurer is the risk of adverse selection, where the only people taking out long-term care policies are people who know that they have a high risk of losing their autonomy. It has been observed that people buying long-term care insurance contracts have a higher probability of becoming disabled than those who do not buy such contracts, ${ }^{6}$ and people who discontinue their contracts have a much lower probability of becoming disabled than those who do not. ${ }^{7}$ This is a classic health insurance risk, which should be treated under identical conditions.

The third risk for the insurer is that of moral hazard. In long-term care, moral hazard has less to do with the behaviour of the policyholder than with his social environment. As we have seen, the perception of long-term care as a risk is a very recent phenomenon. It has less to do with the increasing wealth of society than with the rural exodus and the desire for autonomy of both parents and children, with the result that elderly parents are less and less likely to live under the same roof as their children. This development is certainly nearing its end, but it highlights the point to which the idea of loss of autonomy is determined by the social perception that we have of such loss. This social perception has no reason to stabilise over the next few years. It is even less likely to settle down in that the criteria for loss of autonomy are relatively vague and susceptible to widely varying interpretations depending on the social climate - in the future we may consider that having trouble taking a bath constitutes a loss of autonomy in bathing, etc. The major escalation in handicap allowances, which are still seeing double-digit growth in developed countries, independently of the actual state of health of the populations involved, is a good illustration of what could happen in the future with long-term care. If this risk has not yet tended to materialise for long-term care, it is because the stakes until now have been low. Once long-term care becomes a challenge for society and has its own dedicated rights and laws, etc., the risk of ex post escalation of the content of long-term care insurance contracts signed years before, especially through court decisions, will clearly become a reality. This will happen on three levels:

- the point at which one is considered to have lost autonomy;

- how severe the loss of autonomy is considered to be;

- the level of assistance considered to be normal in relation to a certain degree of loss of autonomy.

In cases where the condition involved is not physiological (e.g. severe rheumatism, physical handicap, etc.), the development of neuropsychiatric criteria could eventually reduce the extent of this moral hazard, because it would link a problem in carrying out an activity of daily life to pathological data that are nonetheless objective.

\footnotetext{
${ }^{6}$ Cf. Finkelstein and McGarry (2003).

${ }^{7}$ Cf. Finkelstein et al. (2005).
} 


\section{Products tailored to this risk}

Economic theory teaches us that, in order to reduce the risk of anti-selection where information is not complete, the principal, which in this case is the insurer, should either:

- obtain private information regarding the agent, in this case the policyholder, in order to be able to distinguish between policyholders and differentiate prices accordingly;

- encourage the agent to come forward himself with a credible indication of his quality as a policyholder, on the basis of which it will be possible to distinguish a price;

- apply the so-called "Stiglitz-Weiss" theorem, using a single price calculated so as not to dissuade good risks but at the same time limiting the overall risk involved.

In actual fact, as the American and French experience has shown, insurers use all three techniques at the same time. A medical questionnaire enables insurers to identify substandard risks, to which an extra premium is applied depending on the long-term prognosis of the condition. With this questionnaire, insurers can also identify the risks linked to a progressive condition, which are then deferred, or to a current loss of autonomy, which are then refused. Moreover, there is a fixed age limit for policies in France - generally set at 75. A waiting period is also imposed, in France usually lasting 1 year in the case of loss of autonomy following an illness and 3 years in the case of neurodegenerative disease. Finally, insurers limit their global commitments in terms of long-term care.

As for the risk of moral hazard, this probably constitutes the greatest challenge for long-term care insurance. The classic solutions recommended by economic theory, namely the sharing of the risk with the agent, control checks, comparative competition, underwriting renewable contracts and merging with the agent, are either not efficient enough (cf. control checks) or prove difficult or even impossible in practice (cf. renewable contracts or merging with the agent) for long-term care. The most recent economic theory developed by Laffont-Tirole ${ }^{8}$ nevertheless shows that in such a case it is optimal for the principal, that is, the insurer, if he does not want to be the residual claimant, to use fixed-price contracts that attribute a fixed sum to the agent, leaving him to spend it on the necessary care at his own discretion. This contrasts with "cost-plus" type contracts, which reimburse all of the costs exhibited by the agent and which are in fact suboptimal because of the incentive they provide for moral hazard.

Focussing on the optimality of fixed-price contracts has several consequences for the definition of long-term care insurance contracts as well as the field in which an efficient level of competition can develop between the various players involved:

- it leads to the promotion of fixed-price payment contracts such as French contracts, as opposed to contracts that reimburse assistance costs such as American contracts, which are typically cost-plus contracts;

\footnotetext{
${ }^{8}$ Cf. Laffont and Tirole (1993).
} 
- for these fixed-price products, competition and innovation should be geared towards offering products that combine the best understanding of the risk with the maximum amount of tailoring to policyholders' needs:

- "gradual" products, that is, products that are proportionate to the need for assistance such as it is evaluated on the basis of the policyholder's objective degree of autonomy loss rather than on the basis of his personal situation;

- "reviewable" products, that is, products where the premium or the nature of the service involved can be reviewed according to the criteria and conditions set out in the terms of the contract;

- "personalised" products thanks to the introduction of increased flexibility (payments in capital or as annuities) and elements of personalised advice (in the field of home equipment, psychological assistance, medical orientation, etc.).

The aim of these products is to be simple and clearly understandable to all potential policyholders when the multiple contract options providing for reimbursement of assistance costs are difficult to understand, because they are difficult to imagine for clients who are, by definition, in good health and totally autonomous when they make their choice. In fact, as the German experience has shown, when policyholders are faced with a choice, they prefer a fixed-sum payment even if it is twice as low as the reimbursement limit for assistance costs. Policyholders, therefore, endorse freedom in the management of assistance.

Whatever might be the consequences, in order to expand in the future, the market for long-term care needs a minimum level of product stability, in order to accumulate sufficient experience and to optimise pricing with respect to risk. This minimum level of stability, which has been lacking on the U.S. market, has probably contributed to the important problems it has been facing.

\section{Conclusion}

Long-term care insurance is a potentially expanding market, even if expansion is not always universally present. It is important that governments do not pre-empt this market, by offering public guarantees for the future, and that insurance companies are able to innovate and design products tailored to this very specific demand. In fact, the market for long-term care is a complex market that requires technical skills, rigour, stability and a level balance between product and distribution.

\section{Acknowledgements}

I thank the participants of The Geneva Association's General Assembly in New York who made precious insightful comments, criticisms and suggestions about a first version of this paper.

\section{References}

Brown, J.R., Coe, N.B. and Finkelstein, A. (2006) Medicaid crowd-out of private long-term care insurance demand: Evidence from the health and retirement survey, NBER working paper no. 12536, Washington, DC. 
Brown, J.R. and Finkelstein, A. (2004) The interaction of public and private insurance: Medicaid and the long-term care insurance market, NBER working paper no. 10989, Washington, DC.

Cambois, E., Clavel, A. and Robine, J.M. (2006) 'L'espérance de vie sans incapacité continue d'augmenter', Solidarité et Santé 2: 7-22.

Finkelstein, A. and McGarry, K. (2003) Private information and its effect on market equilibrium: Evidence from long term care insurance, NBER working paper no. 957, Washington, DC.

Finkelstein, A., McGarry, K. and Sufi, A. (2005) Dynamic inefficiencies in insurance markets: Evidence from long term care insurance, NBER working paper no. 11039, Washington, DC.

Jacobzone, S. (2000) 'Santé et vieillissement: les perspectives de prise en charge de la dépendance', ISUMA 1.

Laffont, J.J. and Tirole, J. (1993) A Theory of Incentives in Procurement and Regulation, Cambridge, MA: MIT Press.

Lafortune, G. and Balestat, G. (2007) Trends in severe disability among elderly people, OCDE Health working paper no. 26, Paris.

Lakdawalla, D. and Philipson, T. (2002) 'The rise in old-age longevity and the market for long-term care', American Economic Review 92: 295-306.

Taleyson, L. (2003) 'L'assurance dépendance privée: comparaisons internationals', Vie - Newsletters techniques SCOR 9: 1-4.

\begin{abstract}
About the Author
Denis Kessler is a graduate of HEC business school (École des Hautes Études Commerciales), with a Ph.D. in Economics, a qualified professorship (agrégé) in Economics and a qualified professorship in Social Sciences. Chairman of the Fédération Française des Sociétés d'Assurance (FFSA) (Federation of French Insurance Companies), and subsequently Senior Executive Vice President and member of the Executive Committee of AXA, Denis Kessler was First Executive ViceChairman from 1999 to 2002 of the Mouvement des Entreprises de France (MEDEF) (French Business Confederation), while continuing to serve as Chairman of the FFSA. He joined SCOR on 4 November 2002 as Chairman and Chief Executive Officer.
\end{abstract}

